This is the author's final, peer-reviewed manuscript as accepted for publication. The publisher-formatted version may be available through the publisher's web site or your institution's library.

\title{
Use of bioethanol byproduct for supplementary cementitious material production
}

Feraidon F. Ataie and Kyle A. Riding

\section{How to cite this manuscript}

If you make reference to this version of the manuscript, use the following information:

Ataie, F. F., \& Riding, K. A. (2014). Use of bioethanol byproduct for supplementary cementitious material production. Retrieved from http://krex.ksu.edu

\section{Published Version Information}

Citation: Ataie, F. F., \& Riding, K. A. (2014). Use of bioethanol byproduct for supplementary cementitious material production. Construction and Building Materials, 51, 89-96.

Copyright: (c) 2013 Elsevier Ltd.

Digital Object Identifier (DOI): doi:10.1016/j.conbuildmat.2013.10.092

Publisher's Link: http://www.sciencedirect.com/science/article/pii/S0950061813010131

This item was retrieved from the K-State Research Exchange (K-REx), the institutional repository of Kansas State University. K-REx is available at http://krex.ksu.edu 


\title{
Use of Bioethanol Byproduct for Supplementary Cementitious Material Production \\ Feraidon F. Ataie and Kyle A. Riding \\ Civil Engineering Department, Kansas State University
}

\begin{abstract}
:
Corn stover has the potential for use as a supplementary cementitious material (SCM) for concrete. The impact of distilled water and dilute acid pretreatments and post-treatments on the pozzolanic reactivity of corn stover ash (CSA) was studied. Additionally, the potential use of a bioethanol byproduct called high lignin residue (HLR) for SCM production was examined. Pretreated CSA and high lignin residue ash (HLRA) increased the early reactivity of cement paste when used as 20\% replacement of cement in the system whereas unpretreated CSA was found to severely suppress the hydration reaction. The highest compressive strength was obtained from samples containing HLRA.
\end{abstract}




\section{Introduction:}

Greenhouse gas emissions from fossil fuel burning have created increasing interest in the use of biomass for renewable energy production. Thermochemical and biochemical conversion techniques have been used to convert biomass, including agricultural residues, to biofuel [1] and [2]. Combustion, gasification, and pyrolysis are widespread thermochemical conversion techniques for converting biomass into electricity and bio-oil. Biochemical conversion of biomass involves hydrolysis of biomass into its constituent sugar followed by sugar fermentation to bioethanol [2] and [3]. Besides biofuel production, biomass has been used for supplementary cementitious materials (SCMs) production to reduce the carbon footprint of concrete [4-6].

Utilization of biomass for either biofuel or SCM production has posed certain challenges. The presence of alkali and alkaline earth metals (AAEMs) in the biomass can adversely affect the quality of the bio-oil and cause slagging and fouling during combustion [7] and [8]. It has been shown that removal of AAEMs out of the biomass prior to pyrolysis by the use of pretreatments improves the yield and the quality of the bio-oil during pyrolysis, and reduces slagging and fouling during combustion [8-12]. Biomass pretreatments are commonly performed by soaking the biomass in acidic or basic solutions [9]. It has also been shown that pretreatments, particularly dilute acid, improve the reactivity of agricultural residue ash (ARA) such as rice husk ash in cementitious systems by increasing the amorphous silica content and surface area of the ash $[4,6$, and 13].

In the biochemical conversion, the biomass undergoes three basic processes: pretreatment, enzymatic hydrolysis, and fermentation [2] and [3]. Pretreatments improve the biomass ethanol yield by increasing the accessibility of cellulose for enzymatic hydrolysis [14]. Enzymatic hydrolysis (saccharification) is performed on the pretreated biomass to convert the cellulose and 
hemicellulose to C5 and C6 sugars. After the enzymatic hydrolysis, the sugar rich liquid phase is seperated from the solid residue, refered to as high lignin residue (HLR) in this paper. The liquid phase is then fermented to ethanol. Simultaneous saccharification and fermentaion (SSF) processes are also common where the solid residue isn't removed until after the enzymatic hydrolysis and fermentaion [15] and [16]. HLR is currently burned in boilers or landfilled. Fig.1 depicts the production process of lignocellolusic ethanol.

The major constituents of HLR are lignin, cellulose, and other inorgranic constituents such as silica. Because HLR contains a high quantity of silica in a weakly polymerized organic structure, it could be a potential resouce for highly reactive SCMs production. If this can be shown, the cost of lignocellulosic ethanol production and the cost of SCMs produced from biomass can be substantially reduced. Additionally, if it can be shown that HLR burned at higher temperatures could result in a highly reactive ash, the HLR can be burned in biolers to produce energy and at the same time the resulting ash can be used as reactive SCM in concrete at no cost. Every year, millions of tonnes of agricultural residues are produced worldwide. In 2012, global wheat, corn, and rice production were about 697 million metric tons (MMt), $884 \mathrm{MMt}$, and $465 \mathrm{MMt}$, respectively [17]. On the basis of residue to grain ratio of 1.3 for wheat, 1 for corn, and 1.4 for rice [18], in 2012 approximately 2.4 billion metric tons of wheat straw, rice straw, and corn stover was produced. These agricultural residues are potential resouces for ARA production for concrete use. Furthermore, increasing worldwide interest in the production of ethanol from aggricultural residues [10], particularly corn stover, could boost the quantity of HLR available for SCM production.

This is the first study on the reactivity of high lignin residue ash (HLRA) in cementitious systems. Also, the impact of distilled water and dilute acide pretreatments on the reactivity of 
corn stover ash (CSA) using different burning conditions was investigated. Pretreated and unpretreated corn stover and HLR were burned at controlled temperatures of $500^{\circ} \mathrm{C}$ and $650^{\circ} \mathrm{C}$ for several different oven residence times. Ash characterizations, heat of hydration, and compressive strength data were used to compare the pozzolanic behavior of pretreated and unpretreated CSA with that of HLRA.

\section{Materials and methods:}

\subsection{Materials:}

An ASTM C150 [19] Type I/II portland cement was used for this study with the cement properties shown in Table 2. Standard graded sand [20] was used for the mortar experiments. Corn stover was purchased from a local farm in Manhattan, KS. The high lignin residue (HLR) material used was the solid residue taken after an SSF process using corn stover as the feedstock material and was supplied by the National Renewable Energy Laboratory at Golden, CO. The HLR material contained $30 \%$ cellulose and $70 \%$ lignin on dry mass. Reagent grade hydrochloric $(\mathrm{HCl})$ and sulfuric acid were obtained and diluted to $0.1 \mathrm{~N}$ for use in the study. Phosphorus pentoxide $\left(\mathrm{P}_{2} \mathrm{O}_{5}\right)$ and potassium hydroxide $(\mathrm{KOH})$ used were ACS grade.

\subsection{Experimental Methods:}

\subsubsection{Treatments:}

Hydrothermal pretreatment methods were performed on chopped corn stover (CS) using distilled water (DW), $0.1 \mathrm{~N} \mathrm{HCl}$, and $0.1 \mathrm{~N}$ Sulfuric acid. To pretreat the biomass, $250 \mathrm{~g}$ of biomass was immersed in $3100 \pm 100 \mathrm{~mL}$ of the solution in a $4000 \mathrm{~mL}$ glass jar. The sample was stored undisturbed at a constant temperature of either $23^{\circ} \mathrm{C}$ or $80^{\circ} \mathrm{C}$ for a given immersion 
period. After immersion, samples of leachate were collected for further analysis. After pretreatments, the biomass was rinsed either twice or four times, each time with $2500 \mathrm{~mL}$ of distilled water and dried at $80^{\circ} \mathrm{C}$ in an oven.

Post-treatment for corn stover ash (CSA) was performed by soaking the $20 \mathrm{gr}$ of ash in 100 gr of distilled water and stirring the slurry for one hour at $23^{\circ} \mathrm{C}$. After stirring, the slurry was filtered and the solid residue (post-treated ash) was dried at $80^{\circ} \mathrm{C}$ in an oven. Leachate samples were collected for further analysis. Leachate Concentrations of magnesium $(\mathrm{Mg})$, calcium $(\mathrm{Ca})$, potassium $(\mathrm{K})$, sodium $(\mathrm{Na})$, and phosphorus $(\mathrm{P})$ were determined using inductively coupled plasma mass spectrometry (ICP-MS).

\subsubsection{Ash production:}

A programmable electric muffle furnace was used to heat the biomass samples to a predetermined temperature and hold time. To prepare corn stover ash (CSA), $200 \mathrm{~g}$ of dried corn stover was burned in each batch made. A stainless steel cage with two wire mesh shelves was used to hold the biomass during burning. A stainless steel pan was placed below the cage to catch any ash that fell through the mesh. High lignin residue ash (HLRA) was prepared by placing 100 gr of HLR on the stainless steel pan and heating in the furnace. Samples were heated to $500^{\circ} \mathrm{C}$ for two hours $(500 / 2)$ or $650^{\circ} \mathrm{C}$ for one hour $(650 / 1)$. Finally, the ash was ground for one hour at 85 revolutions per minute (rpm) in a laboratory ball mill. The naming convention for ash samples is as follows: type of ash-pretreatment-washing times-burning temperature/holding time. Unpretreated samples are labeled "Cont." For example, the name of corn stover ash pretreated with $0.1 \mathrm{~N} \mathrm{HCl}$ at $80^{\circ} \mathrm{C}$ that was washed 4 times after pretreatments and burned at $500^{\circ} \mathrm{C}$ for $2 \mathrm{hrs}$ would be CSA-HCl80-4-500/2. CSA-650/1-Post and CSA-500/2-Post are posttreated CSA-Cont-650/1 and CSA-Cont-500/2 samples, respectively. (OPC+650/1-leachate) and 
$(\mathrm{OPC}+500 / 2$-leachate) are paste samples in which the leachate from the post-treatment of CSACont-650/1 and CSA-Cont-500/2 samples was used as mixing water, respectively.

\subsubsection{Biomass ash characterizations:}

Particle-size distribution and surface area of the ground biomass ash (CSA and HLRA) were determined using a laser diffractometer and BET nitrogen adsorption. Also, backscattered scanning electron microscopy (SEM) images were taken to show the particle shape and size of portland cement and selected ash samples. ARA loss on ignition (LOI) was determined by measuring the mass loss after heating one gram of dry biomass ash (CSA, WSA or RSA) to $900^{\circ} \mathrm{C}$ for $3 \mathrm{hrs}$. LOI was calculated as the percentage mass loss during firing. To determine crystalline phases of the ash samples, $\mathrm{x}$-ray diffraction (XRD) analysis was performed $(\mathrm{Cu} \mathrm{K} \alpha$ radiation with $\lambda=1.5046 \AA$ ). A step size of $0.02^{\circ} / 2 \mathrm{~s}$ and a scan range of $5^{\circ}-70^{\circ} 2 \theta$ was used. The chemical composition of ash samples were determined using x-ray fluorescence (XRF).

\subsubsection{Biomass ash pozzolanic reactivity determination:}

For cement paste experiments, $20 \%$ of the cement was replaced by CSA when used. A water-cementitious materials ratio $(\mathrm{w} / \mathrm{cm})$ of 0.5 was used for all paste samples. Distilled water was added to the cementitious material and mixed using a vertical laboratory mixer at $500 \mathrm{rpm}$ for 90 seconds, followed by a 120 second rest period, and finally mixed at $2000 \mathrm{rpm}$ for 120 seconds [21].

For determining heat of hydration of cement pates, an eight-channel isothermal calorimeter was used in this study. Approximately $30 \mathrm{~g}$ of cement paste was used and the calorimeter was run at $23^{\circ} \mathrm{C}$ for one week. The calcium hydroxide $(\mathrm{CH})$ content of cement paste samples was obtained using thermogravimetric analysis to study the pozzolanic consumption of $\mathrm{CH}$ by biomass ash. Paste samples were cast in polystyrene vials. Samples were wet cured starting at 24 
hrs after casting at $23^{\circ} \mathrm{C}$. Cement paste hydration was stopped at 7,28 , and 91 days of hydration by means of solvent exchange with isopropanol. Approximately $2 \mathrm{~mm}$ thick slices were cut and placed in isopropanol for 7 days. After 7 days in isopropanol, the samples were dried in a vacuum for at least 3 days. Free water content was obtained as the difference between the weight of samples before soaking in isopropanol and after drying. 25 to $30 \mathrm{mg}$ of dried paste was heated at $20^{\circ} \mathrm{C} / \mathrm{min}$ to $900^{\circ} \mathrm{C}$ in a nitrogen environment using a thermogravimetric analyzer (TGA). The $\mathrm{CH}$ content of paste samples was obtained using thermogravimetric analysis.

Mortar cube compressive strength was measured according to ASTM C109 [22] with a sand to cementitious material ratio of 2.75 . A w/cm of 0.55 was used for all mortar samples because of the decreased workability of systems with pretreated CSA samples. CSA was used at a $20 \%$ replacement level by mass of cement when used. Mortar cube compressive strength was tested at 7,28 , and 91 days with the results reported as the average of the compressive strength of three mortar cubes.

\section{Results and discussion:}

\subsection{Biomass ash characteristics:}

The major influence of pretreatments seen is the removal of metal impurities out of the biomass. Table 1 shows the amount of metal impurities removed by the pretreatments out of the corn stover. The data shows that all of the pretreatments removed similar amounts of potassium (K). However, distilled water pretreatments did not remove as much $\mathrm{Ca}, \mathrm{Mg}$, and $\mathrm{P}$ as the dilute acid pretreatments.

The effect of removing the impurities was reflected in the physical and chemical properties of the CSA. Pretreatments decreased the crystallinity of the ash. Fig. 2 shows the XRD results of pretreated and unpretreated corn stover ash burned at $650^{\circ} \mathrm{C}$ for one hour. Unpretreated 
corn stover ash (CSA-Cont-650/1) had higher crystalline content compared to the pretreated samples (CSA-HCl80-2-650/1 and CSA-HCl80-4-650/1). The major crystalline phases in the unpretreated ash were sylvite (potassium chloride) and $\mathrm{KCaPO}_{4}$. Although pretreatments removed most of the potassium out of the biomass, pretreated ash still contained some potassium chloride as can be seen in CSA-HCl80-2-650/1 sample. However, CSA-HCl80-4-650/1 showed low intensity XRD peaks for potassium chloride and larger amorphous hump than that of CSAHCl80-2-650/1. Pretreated and unpretreated ash samples contained crystalline quartz. HCl80 pretreated CSA burned at $500^{\circ} \mathrm{C}$ for $2 \mathrm{hrs}$ showed similar XRD patterns in Fig. 3 to that of $650^{\circ} \mathrm{C}$ for $1 \mathrm{hr}$. Corn stover ash pretreated with distilled water (DW80) showed different XRD patterns than the ash pretreated by $\mathrm{HCl} 80$ as shown in Fig. 4. The major crystalline phases in the DW80 pretreated samples were calcite and quartz. $\mathrm{HCl} 80$ pretreated corn stover ash had a larger amorphous hump than the DW80 pretreated sample, suggesting that the former had a higher amorphous content. Furthermore, CSA pretreated with sulfuric acid (Sul80) did not show sylvite phase, as illustrated in Fig.5. Besides quartz, potassium sulfate was the second major crystalline phase in the dilute sulfuric acid pretreated CSA (CSA-Sul80-4-500/2). Although HLRA contained some quartz, neither potassium chloride nor calcite phases were found in the samples, as can be seen in Fi. 5 .

The presence of crystalline potassium chloride phases in unpretreated and $\mathrm{HCl}$ pretreated corn stover ash samples suggests that the potassium in the biomass reacts with chlorine during the burning to form potassium chloride $(\mathrm{KCl})$. The absence of $\mathrm{KCl}$ in the ash sample pretreated with Sul 80 could be because the pretreatment removed the chlorine out of the biomass and the acid did not provide an additional supply of $\mathrm{Cl}$ like the $\mathrm{HCl}$ did. Instead, potassium sulfate was formed in Sul80 pretreated samples. Potassium removal from the biomass leads to a decrease in 
biomass ash crystallinity because the potassium easily reacts with other anions during ashing [11]. Moreover, the existence of high amounts of calcite in the DW80 pretreated CSA could be because DW80 removed less calcium out of the biomass compared to Sul80 and HCl80 pretreatments because acids can dissolve many calcium bearing phases that could be found in the stover.

Besides the change in biomass ash crystalline content, pretreatments also changed the chemical composition of the biomass ash. Pretreatments increased the silica content of the biomass ash by reducing the carbon content (LOI) and other metal oxide impurities in the ash, as shown in Table 2. HLRA had higher silica content compared to the other CSA samples. Pretreatments increased the ash specific surface area. Pretreatments, particularly dilute acid, dramatically reduced the LOI of the biomass ash as illustrated in Table 3. Additionally, the LOI was reduced by increasing the number of rinsing times during pretreatments. This could be because of removal of metal impurities, particularly potassium, from the biomass surface during rinsing. The lowest LOI was obtained for HLRA followed by the ash pretreated with dilute sulfuric acid (Sul80). The higher surface area and lower LOI of HLRA compared to dilute acid pretreated CSA could be attributed to the removal of cellulose out of the biomass and to the structural change of lignin by enzymatic hydrolysis and also to the lower metal impurities, particularly potassium, content of HLR compared to that of dilute acid pretreated corn stover. Removal of cellulose and structural change of lignin could cause the lignin and the remaining organic compounds in the HLR to better burn off leading to lower LOI and higher surface area for HLRA. HLRA showed an overall smaller particle size distribution than other CSA as shown in Fig. 6. SEM images revealed that HLRA-650/1 had similar particle size distribution to that of the cement whereas CSA-HCl-650/1 had elongated and planer particlese, as shown in Fig. 7. The 
high surface are of CSA and HLRA samples can be attributed to thier high surface defects and porosity as can be seen in Fig. 7b,c.

\subsection{Biomass ash pozzolanic reactivity:}

\subsubsection{Heat of hydration}

Pretreatments and post-treatments dramatically increase CSA early heat of hydration. Unpretreated CSA suppressed cement hydration whereas CSA pretreated by either distilled water or dilute acid improved the early hydration, as shown in Fig. 8a. Additionally, the pretreatment temperature seemed to have little impact on the early hydration behavior, as shown in Fig. 8b. Although samples containing CSA pretreated with dilute acid showed shorter induction periods than those containing CSA pretreated with distilled water (DW), the total heat of hydration during the first $24 \mathrm{hrs}$ is similar for all paste samples containing pretreated CSA, as illustrated in Fig. 9a. However, after 24 hrs of hydration, samples containing CSA pretreated with dilute acid, either $\mathrm{HCl}$ or sulfuric acid, showed a higher heat of hydration than those containing CSA pretreated with DW, see Fig. 9b. While paste samples containing HLRA showed a shorter dormant period than samples containing dilute acid pretreated CSA, the total heat of hydration of both samples was similar, as shown in Fig. 10. The total heat of hydration of paste samples containing pretreated CSA or HLRA at one day was almost the same as the total heat of hydration of OPC samples at 5 days of hydration. Although the unpretreated CSA retarded the hydration reaction, the total heat of hydration of paste samples containing unpretreated CSA, either CSA-Cont-650/1 or CSA-Cont-500/2, was higher than OPC samples. Paste samples containing CSA-Cont-500/2 showed similar total heat of hydration at five days as those containing pretreated CSA as it can be seen from Fig. $10 \mathrm{~b}$. 
Post-treatments were effective in eliminating the excessive retardation seen with CSA, as shown in Fig. 11. Noticeably, the heat of hydration of (OPC+500/2-leachate) sample was similar to the paste sample containing CSA-500/2-Post. However, (OPC+650/1-leachate) sample showed suppressed hydration similar to the paste sample containing CSA-Cont-650/1.

There could be several factors influencing the hydration behavior of CSA. Pretreatments removed some phosphorous out of the biomass, reduced the LOI and crystallinity of the biomass ash and increased the silica content and surface area of the ash. Amongst these factors, the phosphorus $(\mathrm{P})$ removal and the increase in specific surface area could play a major role in enhancing the early reaction of pretreated CSA. An increase in the ash surface area increases the number of nucleation sites for precipitation of calcium-silicate-hydrate (CSH) which could increase the early heat of hydration [23]. The impact of phosphorus and potassium on cement hydration was studied by adding $0.5 \mathrm{wt} \%$ (weight percent of dry cement) of phosphorus pentoxide or potassium hydroxide to cement paste, respectively. Phosphorus retarded the cement hydration similar to that seen in the unpretreated CSA, whereas added potassium had only minimal impact on early hydration behavior as shown in Fig. 12. While the unpretreated CSA ashed at $650^{\circ} \mathrm{C}$ showed similar hydration to the mixture with added phosphorous, there seems to be other factors affecting the hydration of the CSA containing cement paste samples. The leachate from the CSA ashed at $500^{\circ} \mathrm{C}$ showed a low phosphorous content as shown in Table 4 , and no retardation; however the corresponding post-treated CSA also showed no retardation. It is possible that the form of phosphorus found in the CSA-Cont-500/2 leaches more at high $\mathrm{pH}$ values seen in pore solutions, but not in the post treatment leachate. Since some of the phosphorous was removed by post-treatment, the amount of phosphorus released into the paste from CSA-500/2-Post might not be enough to cause retardation. While it is possible that the high 
level of phosphorous in the leachate from CSA-Cont-650/1 could be the reason behind the hydration suppression in $\mathrm{OPC}+650 / 1$-leachate sample, clearly the cause is more complex.

\subsubsection{Calcium hydroxide consumption and mortar compressive strength:}

The calcium hydroxide $(\mathrm{CH})$ content of cement paste samples containing CSA was less than that of OPC samples, as shown in Fig. 13. The $\mathrm{CH}$ content of OPC paste samples increased with time. The $\mathrm{CH}$ content of samples containing unpretreated CSA (CSA-cont-500/2 and CSA-Cont650/1) remained constant or increased between 7 and 91 days of hydration. Samples containing DW80 pretreated ash (CSA-DW80-4-650/1 and CSA-DW80-4-500/2) did not show a reduction in the $\mathrm{CH}$ content over time. This could be because these ashes had a lower reactivity and the $\mathrm{CH}$ consumption was balanced by the continued cement reaction and $\mathrm{CH}$ production. For more reactive ashes, such as dilute acid pretreated ones and HLRA, the $\mathrm{CH}$ consumption rate was higher than the $\mathrm{CH}$ production rate, lowering the $\mathrm{CH}$ content after 7 days. It was seen that samples containing CSA burned at $500^{\circ} \mathrm{C}$ for 2 hours $(500 / 2)$ had lower $\mathrm{CH}$ content that those containing CSA burned at $650^{\circ} \mathrm{C}$ for 1 hour $(650 / 1)$. This could be attributed to the higher surface area of samples burned at 500/2. Samples containing HLRA-500/2 showed the lowest $\mathrm{CH}$ content at 28 and 91 days of age.

The small increase in compressive strength from 7 to 91 days in the samples made with the unpretreated CSA ash (CSA-Cont-650/1), as shown in Fig. 14, suggests that the addition of unpretreated ash limited the cement reaction. Mortar samples containing CSA-HCl80-2-650/1 and CSA-HCl80-4-650/1 showed higher strength than those without CSA (OPC samples). For mortar samples containing portland cement only (OPC samples) an increase in compressive strength of mortar cubes was associated with an increase in $\mathrm{CH}$ content of paste samples, as shown in Fig. 15. This is because as the hydration reaction of cement continues more $\mathrm{CH}$ is 
produced. However, for samples containing pretreated CSA or HLRA as the compressive strength increases, the $\mathrm{CH}$ content reduces, as it can be seen in Fig. 15. In this case, the pozzolanic reaction of pretreated ash samples is evident because a reduction of $\mathrm{CH}$ content was associated with an increase in compressive strength. The reason for the lower $\mathrm{CH}$ content and accompanying decrease in compressive strength is that the unpretreated CSA samples (CSACont-500/2 and CSA-Cont-650/1) suppressed the cement reaction and provided very little pozzolanic reaction on its own.

Post-treatment improved the compressive strength by $46 \%$ at 7 days and by $67 \%$ at 28 days compared to the unpretreated (control) ash, however the post-treated ash compressive strength was still only $91 \%$ and $87 \%$ of the OPC sample at 7 days and 28 days, respectively. It was also seen that the number of times rinsing the sample after soaking had a negligible effect on the compressive strength since both CSA-HCl80-2-650/1 and CSA-HCl80-4-650/1 had similar compressive strength. Among mortar samples containing biomass ash burned at $650^{\circ} \mathrm{C}$, the

highest mortar compressive strength was obtained from samples containing HLRA-650/1. Use of $20 \%$ HLRA-650/1 increased the 28 days compressive strength by $32 \%$ compared to OPC samples. However, mortar samples containing CSA-HCl80-4-500/2 showed 22\% higher compressive strength than those containing CSA-HCl80-4-650/1 at 28 days. This could be associated with the high surface area of the ash burned at 500/2.

\section{Conclusions}

The pozzolanic properties of high lignin residue ash (HLRA) and the impact of pretreatments on the pozzolanicity of corn stover ash (CSA) were studied. The findings of this study can be summarized as follows: 
1. It was found that pretreatments improve the pozzolanic properties of CSA by removing AAEMs out of the biomass. It was shown that the existence of potassium and calcium in the biomass cause the formation of crystalline phases in the ash.

2. Pretreatments, particularly dilute acid, reduced the crystallinity of the corn stover ash, increased surface area, and reduced LOI of the ash. At a given burning condition, it was shown that HLRA had the highest surface area and the lowest LOI.

3. Unpretreated CSA suppressed the hydration reaction when mixed in cement paste. Also, the mortar samples containing 20\% unpretreated CSA, namely CSA-Cont-650/1 and CSA-Cont-500/2, as cement replacement showed lower compressive strength than control (OPC) mortar samples. It is possible that phosphorus can be leached from the unpretreated CSA into the pore solution retarding hydration.

4. Post-treatments with distilled water at room temperature improved the hydration reaction by removing AAEMs and phosphorus out of the CSA. More phosphorus was removed in the post-treatment from the CSA-Cont-650/1 compared to CSA-Cont-500/2.

5. When used as $20 \%$ cement replacement level, dilute acid pretreated CSA increased the mortar compressive strength significantly. It was found that burning at lower temperatures increased the ash reactivity, even at temperatures lower than that typically needed to melt the silica.

6. HLRA was shown to have excellent pozzolanic reactivity, even higher than those pretreated by dilute acid. This is because of higher amorphous silica content, higher surface area, and lower LOI of the HLRA compared to other CSA samples. The improved pozzolanic performance of HLRA could be attributed to the impacts of 
enzymatic hydrolysis on the biomass chemical and physical properties. This could be mainly because of the organic material depolymerization.

\section{Acknowledgements:}

Financial support for this project was provided by the National Science Foundation (CMMI103093). The author thanks NREL for the supply of HLR materials. The help of Dr. Kenneth J. Klabunde for providing access to the BET Nitrogen equipment is appreciated. The help of Central Plains Cement LLC in chemical analysis of samples is greatly acknowledged. Antoine Borden's assistance with the pretreatment experiments is gratefully acknowledged.

\section{References:}

[1] H. Goyal, D. Seal and S. R.C., "Bio-fuels from thermochemical conversion of renewable resources: A review," Renewable \& Sustainable Energy Reviews, vol. 12, pp. 504-517, 2008.

[2] D. Humbird, R. Davis, L. Tao, D. Kinchin, A. Aden, P. Schoen, J. Lukas, B. Olthof, M. Worley, D. Sexton and D. Duggeon, "Process Design and Economics for Biochemical Conversion of Lignocellulosic Biomass to Ethanol," National Renewable Engergy Labratory, Golden, CO, 2011.

[3] B. C. Saha, L. B. Iten, M. A. Cotta and V. Y. Wu, "Dilute acid pretreatment, enzymatic saccharification and fermentation of wheat straw to ethanol," Process Biochemistry, vol. 40, pp. 3693-3700, 2005.

[4] Q. Feng, H. Yamamichi, M. Shoya and S. Sugita, "Study on the pozzolanic properties of 
rice husk ash by hydrochloric acid pretreatment."," Cement and Concrete Research, vol. 34, no. 3, pp. 521-526, 2004.

[5] A. El-Damatty and I. Hussain, "An economical solution fo the environmental problem resulting from disposal of rice straw," in ERTEP, Ghana, Africa, 2007.

[6] F. F. Ataie and K. A. Riding, "Thermochemical Pretreatments for Agricultural Residue Ash Production for Concrete," Journal of Materials in Civil Engineering, vol. 25, no. 11, p. 1703-1711, 2013.

[7] D. Mourant, Z. Wang, M. He, S. Wang, M. Garcia-Perez, K. Ling and C.-Z. Li, "Mallee wood fast pyrolysis: Effects of alkali and alkaline earth metallic species on the yield and composition of bio-oil," Fuel, vol. 90, no. 9, p. 2915-2922, 2011.

[8] A. Bridgwater, "Review of fastpyrolysis of biomass and product upgrading," Biomass and Bioenergy, vol. 38, p. 68-94, 2012.

[9] Y. Zheng, Z. Pan and R. Zhang, "Overview of biomass pretreatment for cellulosic ethanol production," International Journal of Agricultural and Biological Engineering, vol. 2, no. 3, pp. 51-68, 2009.

[10] A. Koltermann, "Cellulosic Ethanol: Future's Fuel," CHEManager Europe, München, 2011.

[11] L. L. Baxter, T. R. Milesb, T. R. J. Miles, B. M. Jenkins, T. Milne, D. Dayton, R. W. Bryers and L. L. Oden, "The behavior of inorganic material in biomass-fired power boilers: field and laboratory experiences," Fuel Processing Technology, vol. 54, no. 1-3, pp. 47-78, 1998.

[12] D. Nutalapati, R. Gupta, B. Moghtaderi and T. Wall, "Assessing slagging and fouling during biomass combustion: A thermodynamic approach allowing for alkali/ash reactions," Fuel Processing Technology, vol. 88, pp. 1044-1052, 2007. 
[13] A. Salas, S. Delvasto, R. M. Gutierrez and D. Lange, "Comparison of two processes for treating rice husk ash for use in high performance concrete," Cement and Concrete Research, vol. 39, pp. 773-778, 2009.

[14] P. Alvira, E. Tomas-Pejo, M. Ballesteros and M. Negro, "Pretreatment technologies for an efficient bioethanol production process based on enzymatic hydrolysis: A review," Bioresource Technology, vol. 101, pp. 4851-4861, 2010.

[15] M. Ballesteros, J. Oliva, M. Negro, P. Manzanares and I. Ballesteros, "Ethanol from lignocellulosic materials by a simultaneous saccharification and fermentation process (SFS) with Kluyveromyces marxianus CECT 10875," Process Biochemistry, vol. 39, pp. 1843$1848,2004$.

[16] N. Dowe and J. McMillan, "SSF Experimental Protocols-Lignocellulosic Biomass Hydrolysis and Fermentation," NREL, Golden, CO, 2008.

[17] USDA, "World Agricultural Supply and Demand Estimates," United States Department of Agricultural, 2013.

[18] S. Kim and B. E. Dale, "Global potential bioethanol production from wasted crops and crop residues," Biomass and Bioenergy, vol. 26, pp. 361-375, 2004.

[19] A. Standard, "Standard Specification for Portalnd Cement," ASTM International, West Conshohocken, PA, 2009.

[20] A. Standard, "C778-12 Standard Specification for Standard Sand," ASTM International, West Conshohocken, PA, 2012.

[21] K. Riding, D. Silva and K. Scrivener, "Early age strength of blend cement systems by CaCl2 and diethanol-isopropanolmine," Cement and Concrete Research, vol. 40, no. 6, pp. 935 - 
946, 2010.

[22] A. Standard, "ASTM C109-Standard Test Method for Compressive Strength of Hydraulic Cement Mortars," ASTM International, West Conshohocken, PA, 2008.

[23] K. Scrivener and A. Nonat, "Hydration of cementitious materials, present and future," Cement and Concrete Research, vol. 41, no. 7, pp. 651-665, 2011. 


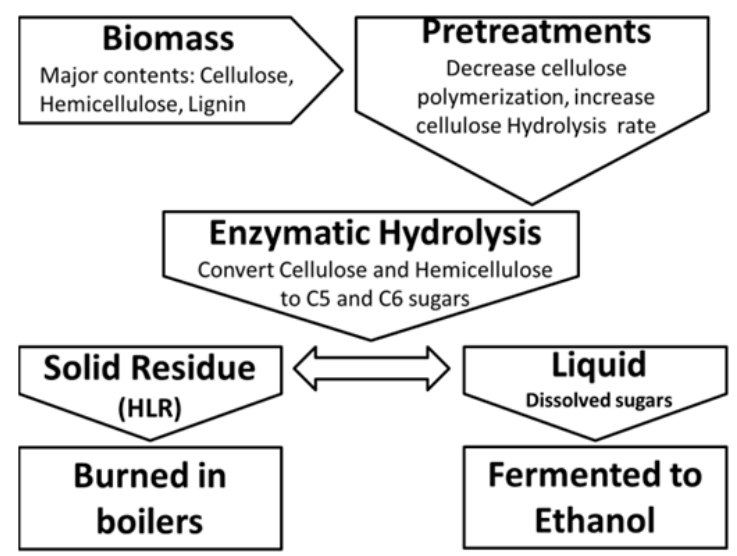

Fig. 1: Bioethanol production process

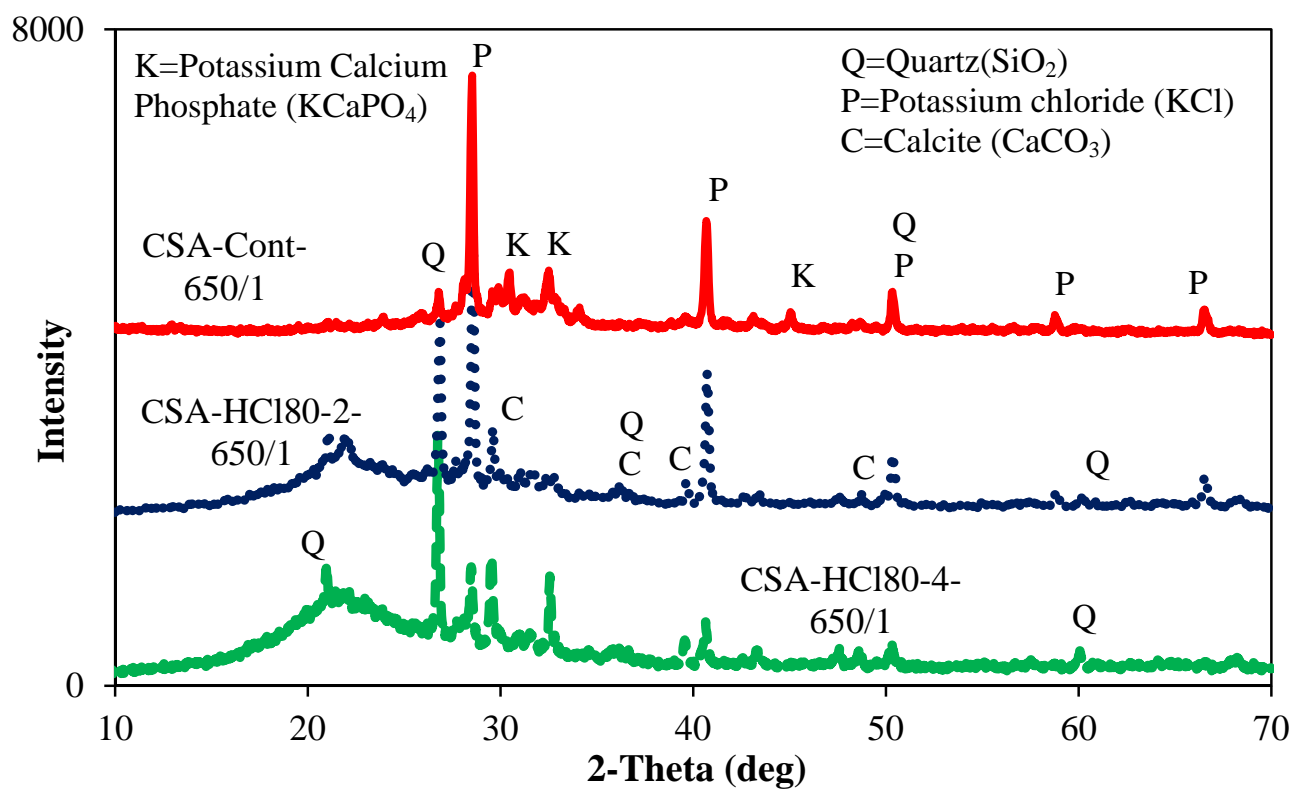

Fig. 2: XRD result for corn stover ash burned at $650^{\circ} \mathrm{C}$ for $1 \mathrm{hr}$. 


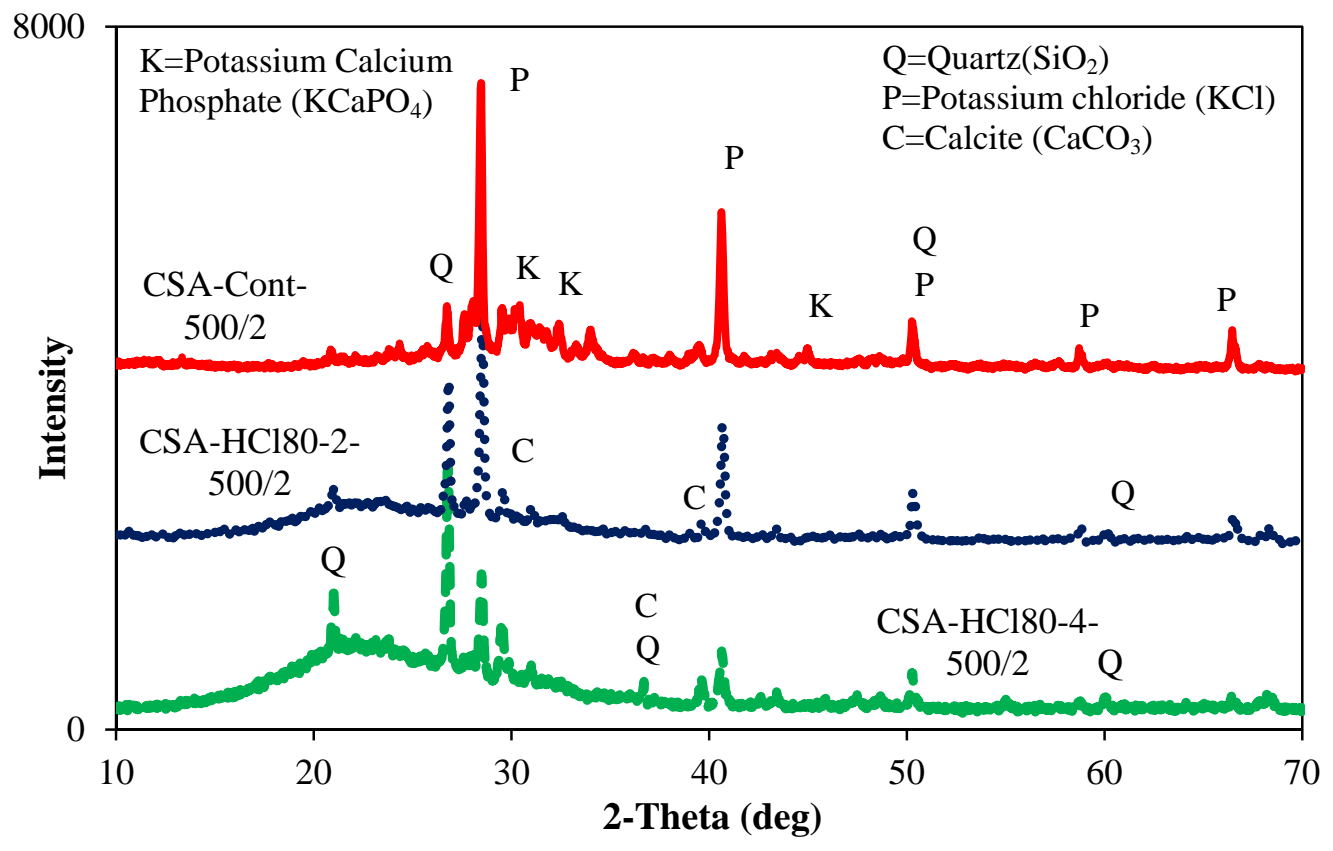

Fig. 3: XRD result for corn stover ash burned at $500^{\circ} \mathrm{C}$ for $2 \mathrm{hr}$

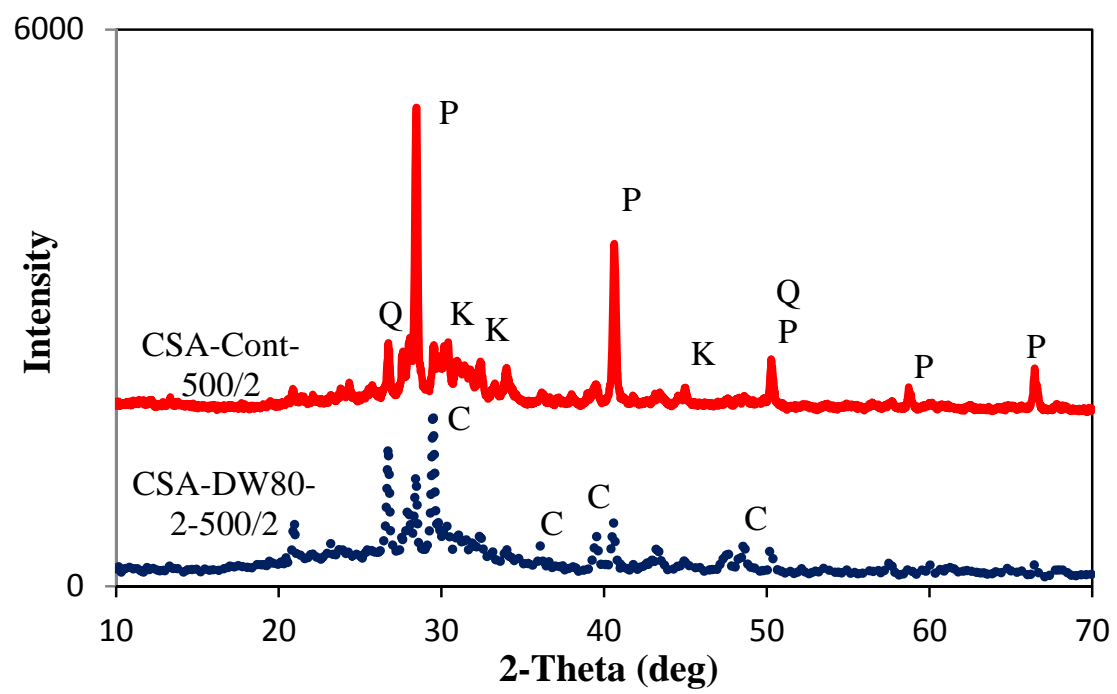

Fig. 4: XRD pattern for CSA pretreated with DW80 


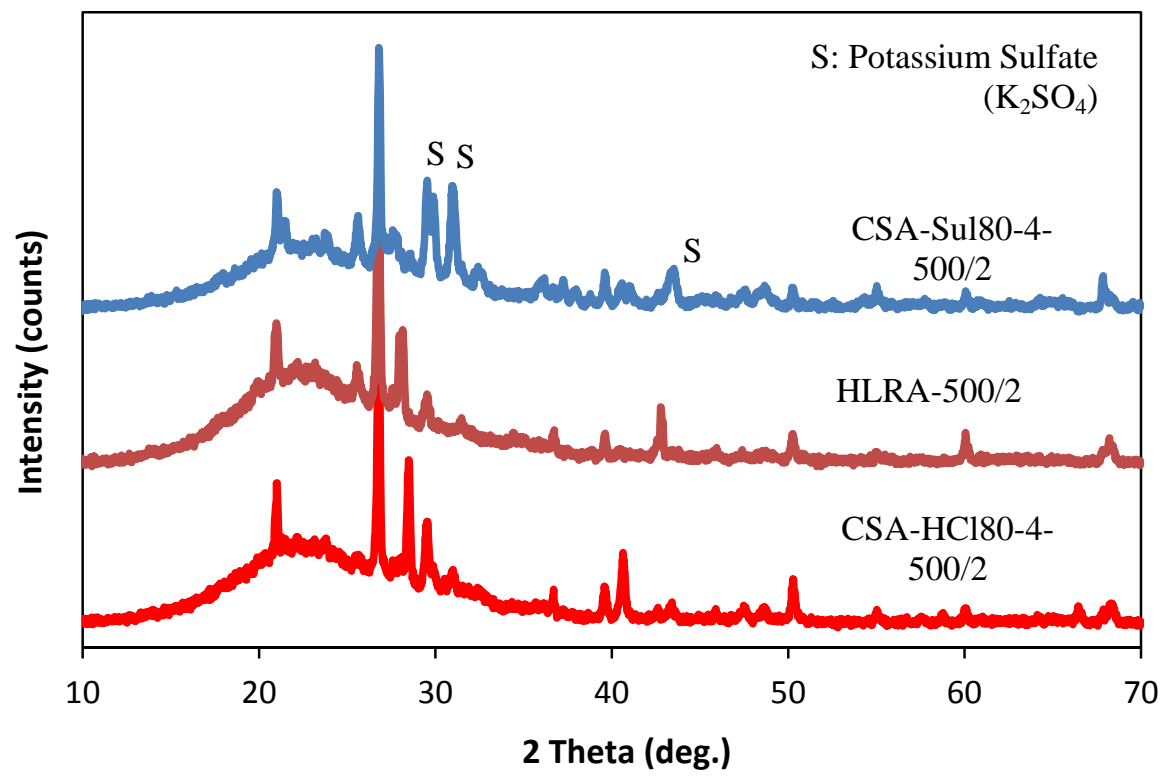

Fig. 5: XRD pattern for HLRA and dilute acid pretreated CSA

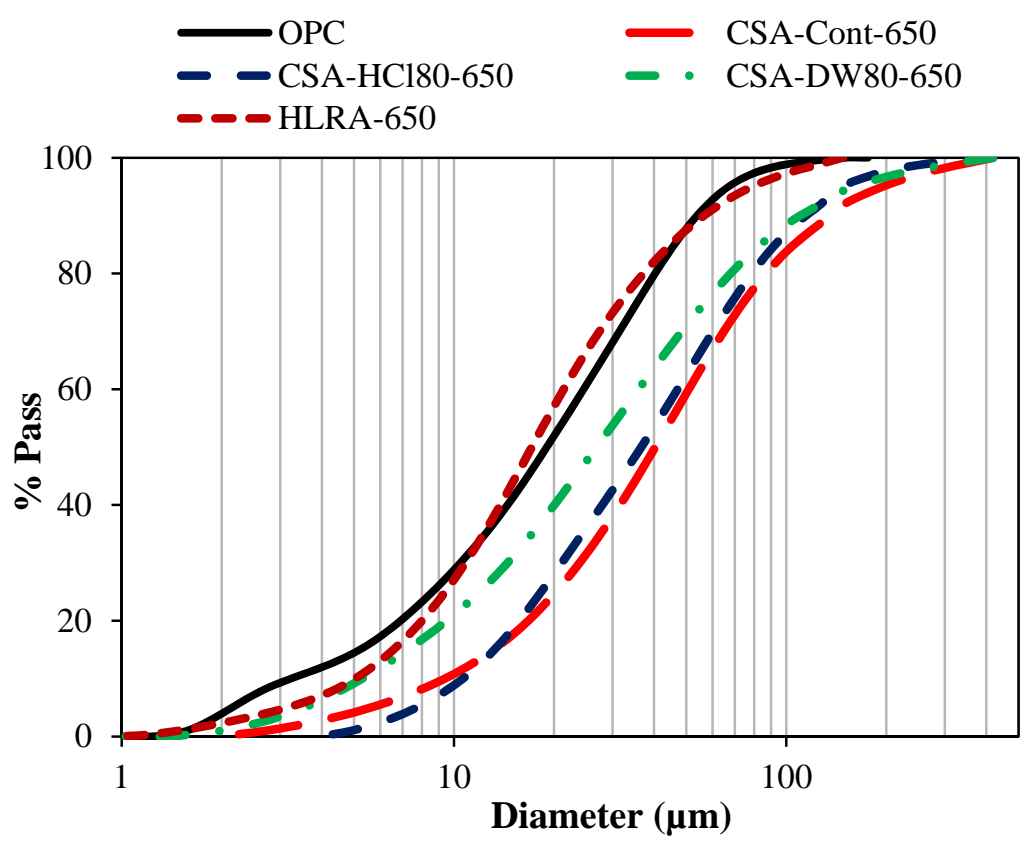

Fig. 6: Particle sized distribution of cement and biomass ash 


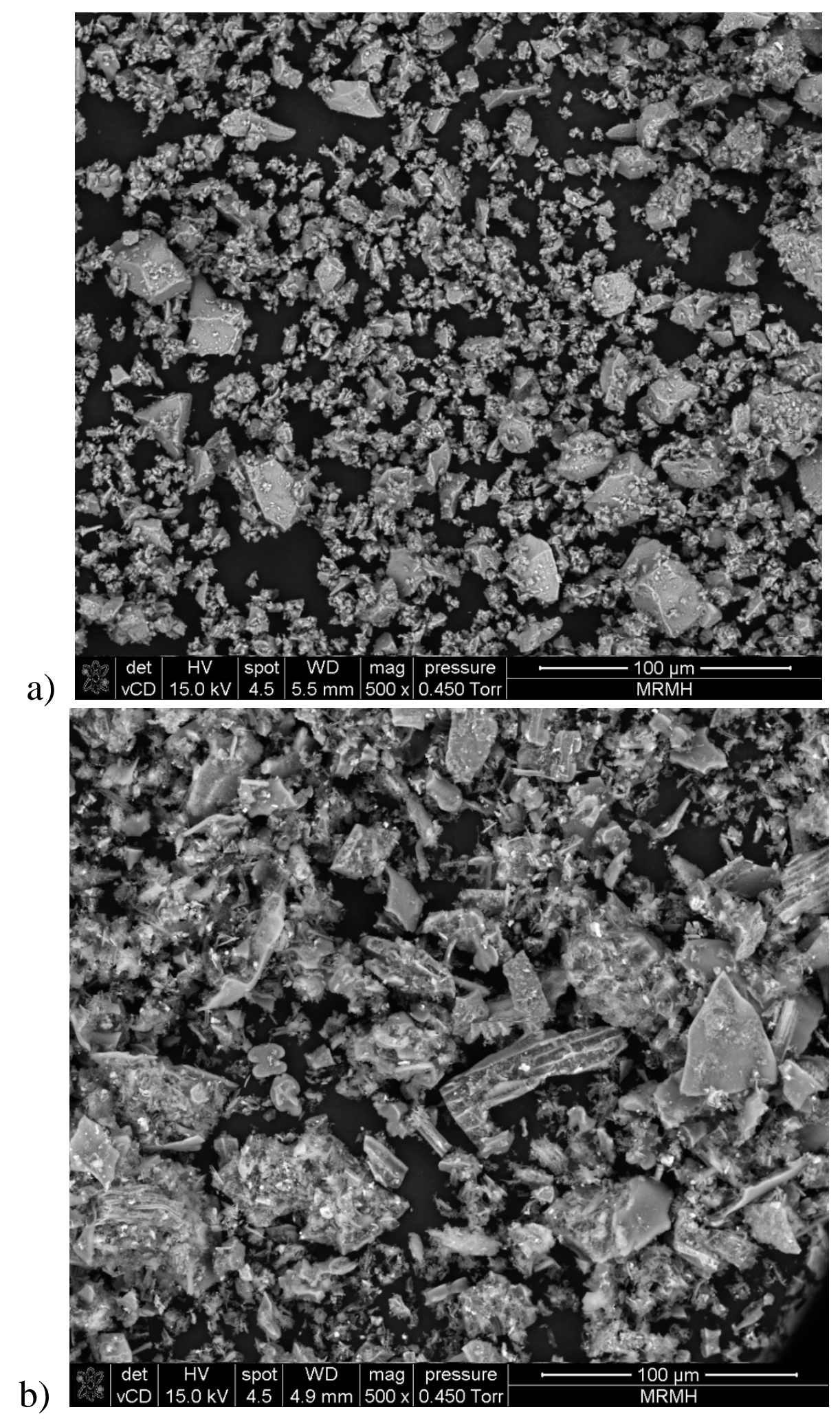




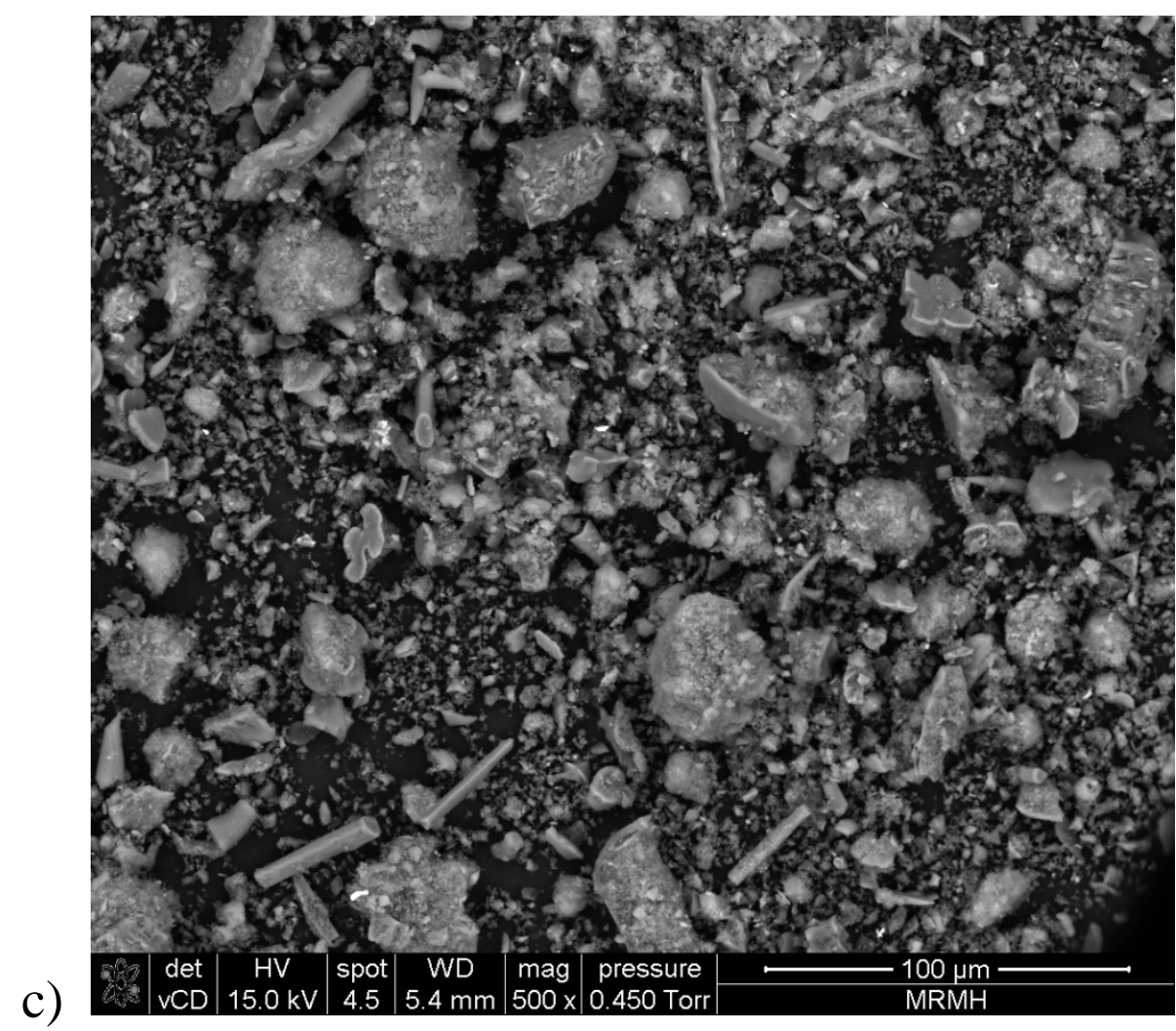

Fig. 7: SEM images of a) portland cement, b) CSA-HCl80-650/1, and c) HLRA-650/1 samples 

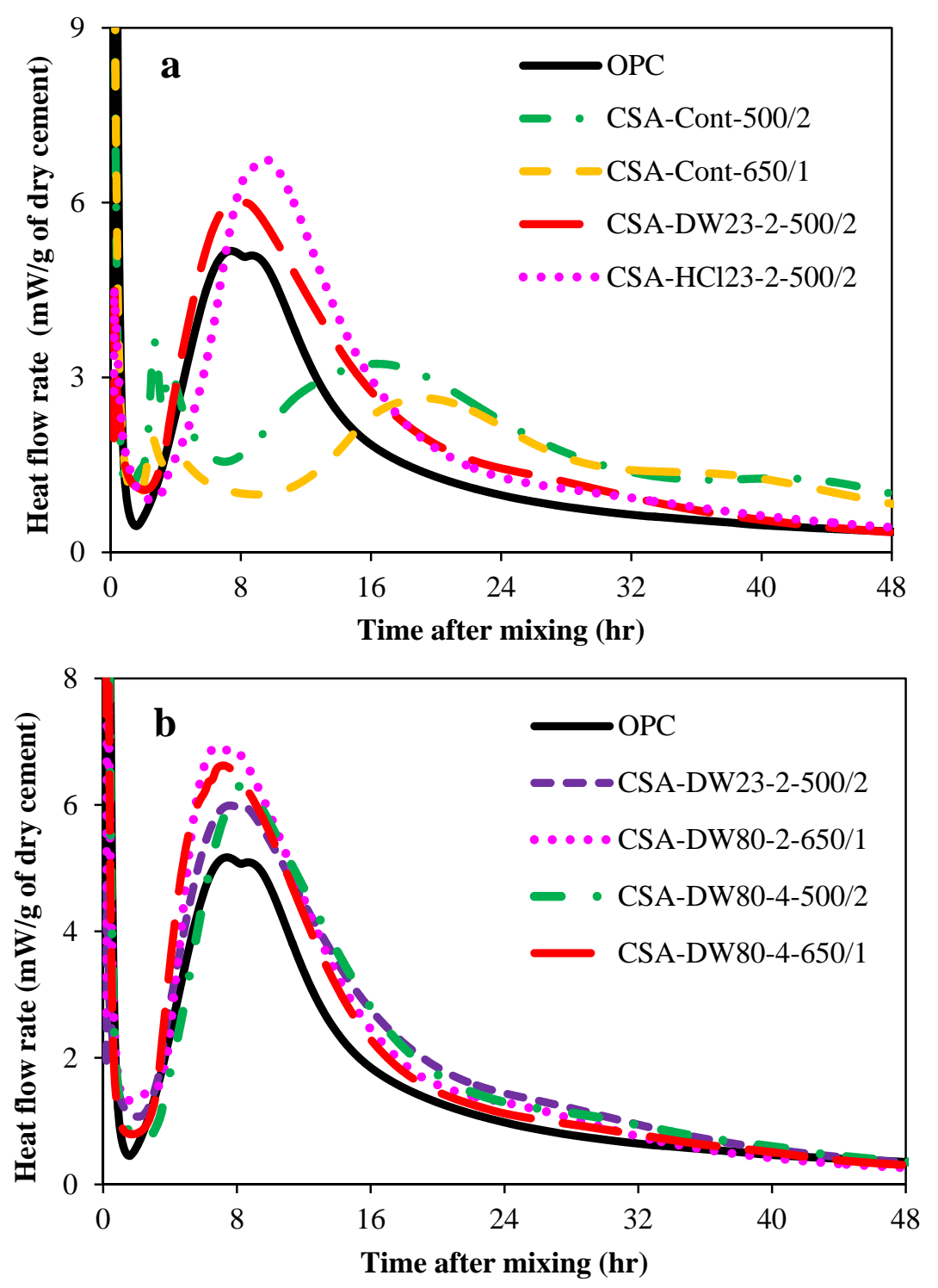

Fig. 8: Heat of hydration of pretreated and unpretreated (Cont.) CSA 

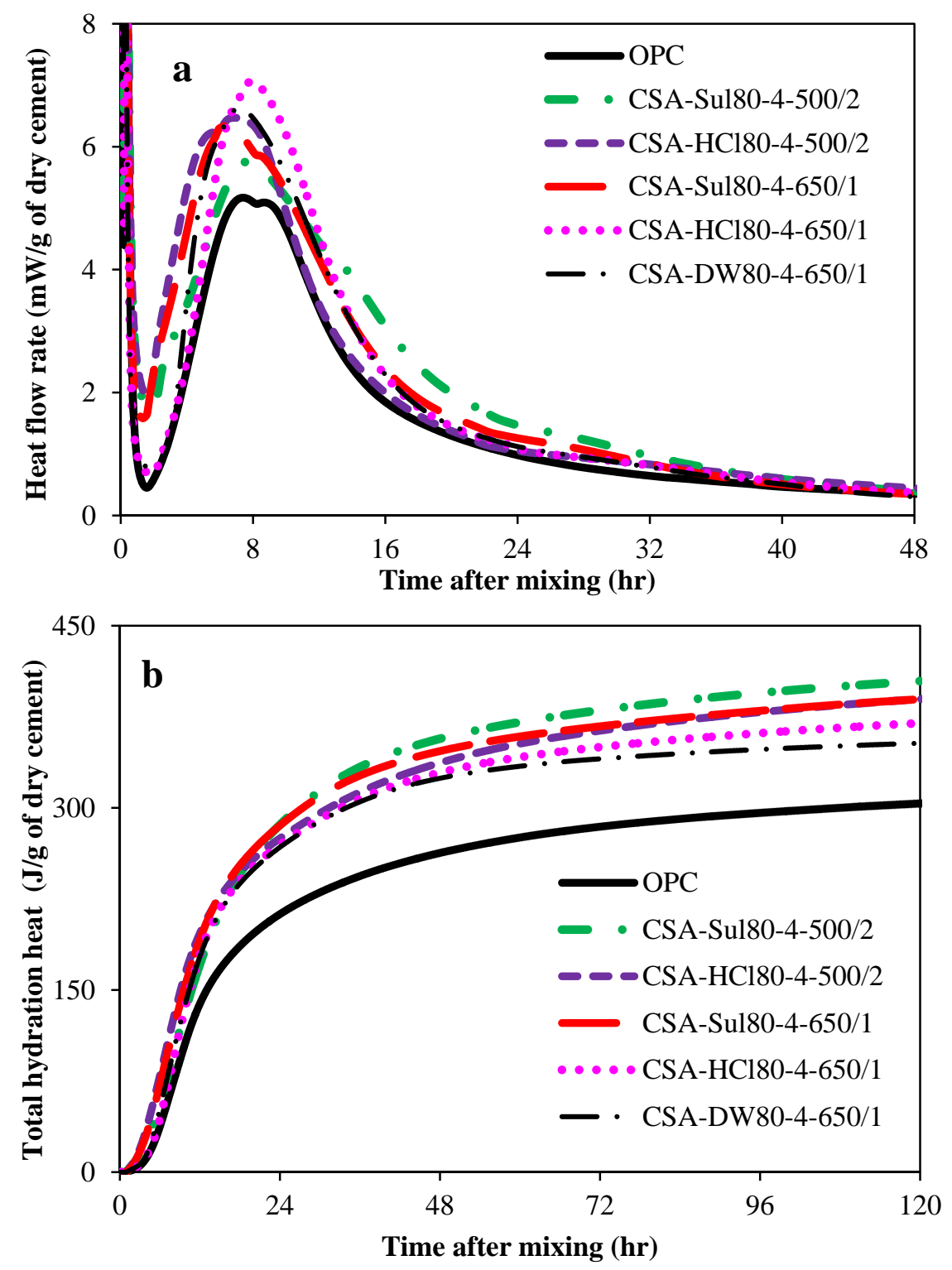

Fig. 9: Heat of hydration of dilute acid pretreated CSA. a) Heat flow rate and b) Cumulative heat 

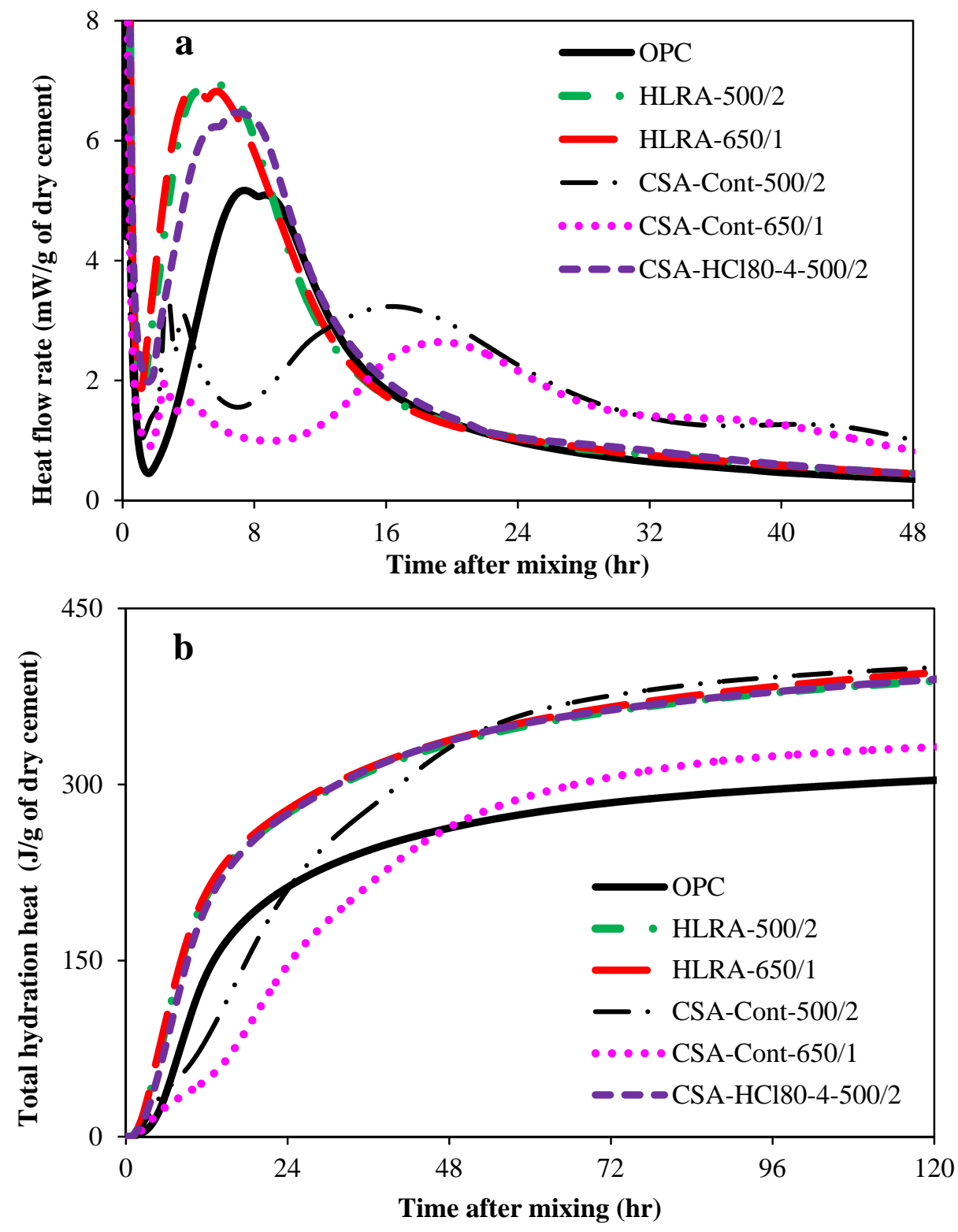

Fig. 10: Heat of hydration of HLRA. a) Heat flow rate and b) Cumulative heat 


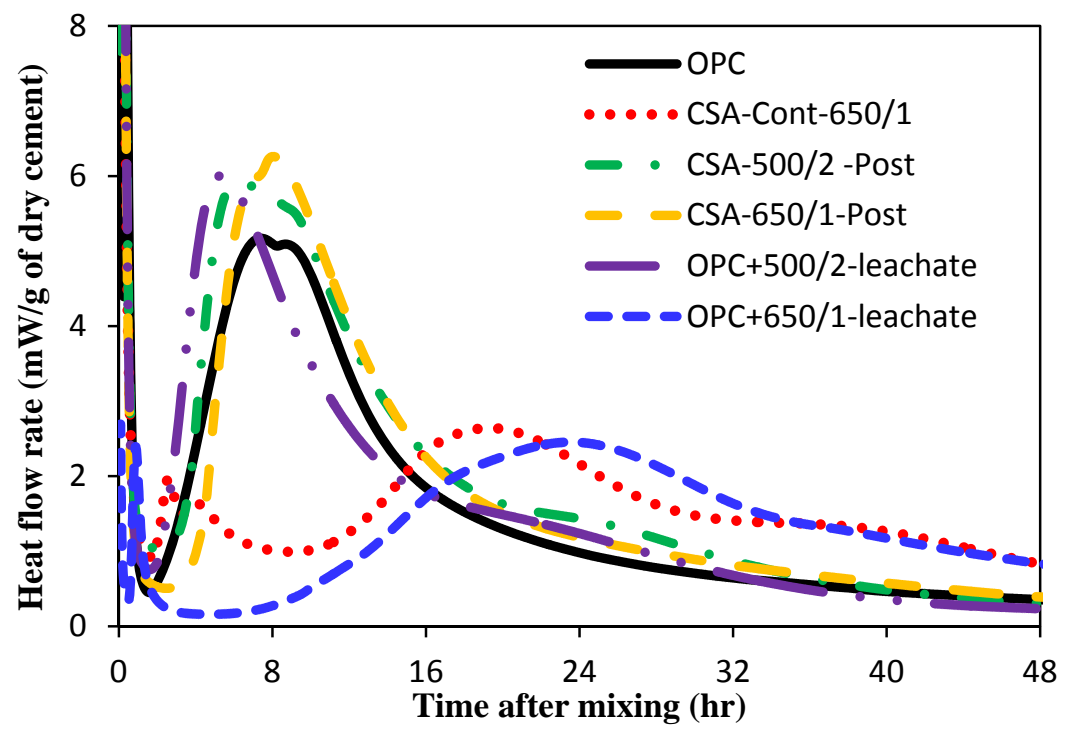

Fig. 11: Heat of hydration of post-treated CSA 

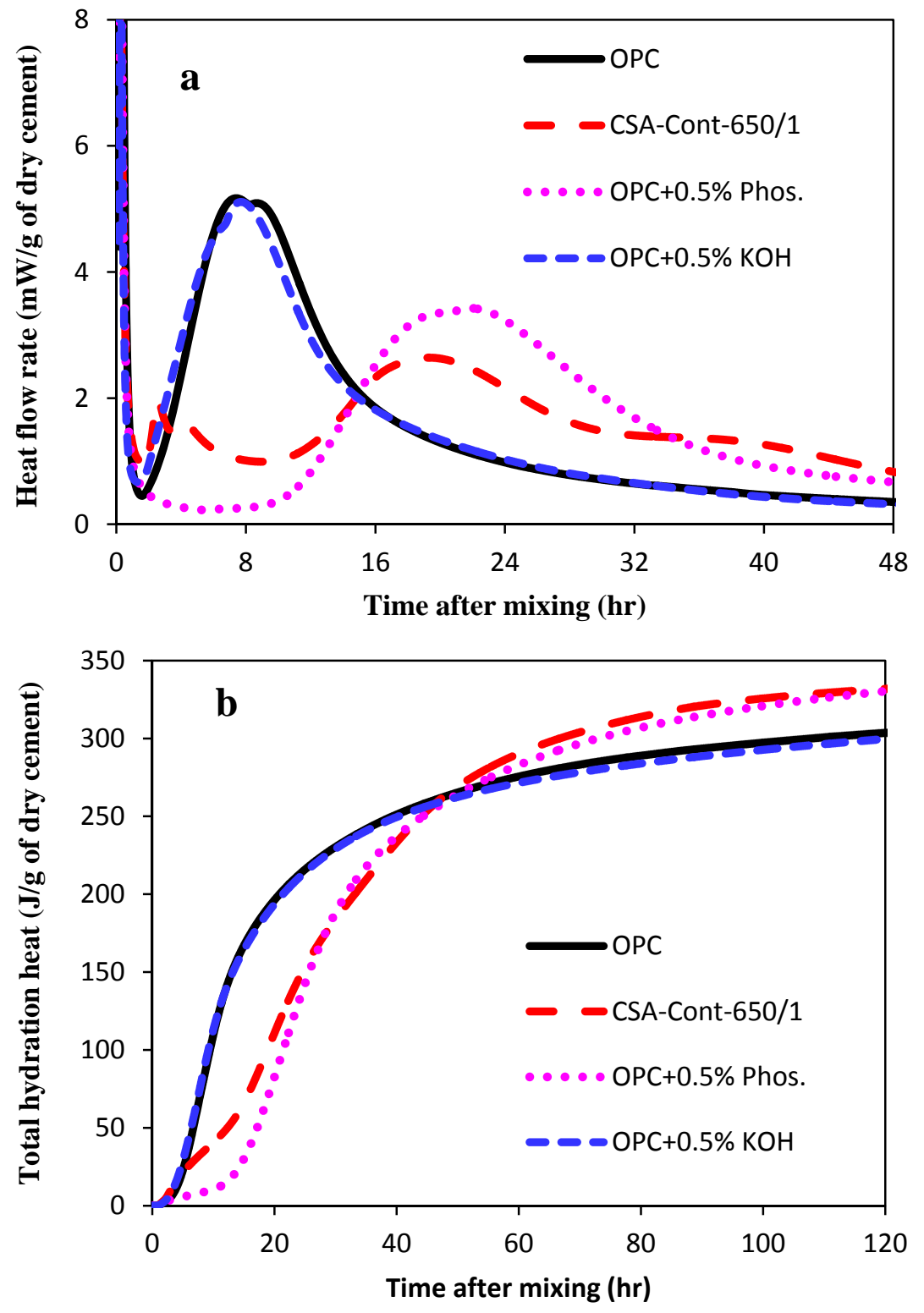

Fig. 12: Cement hydration under phosphorus and $\mathrm{KOH}$. a) Heat flow rate and b) Cumulative heat 


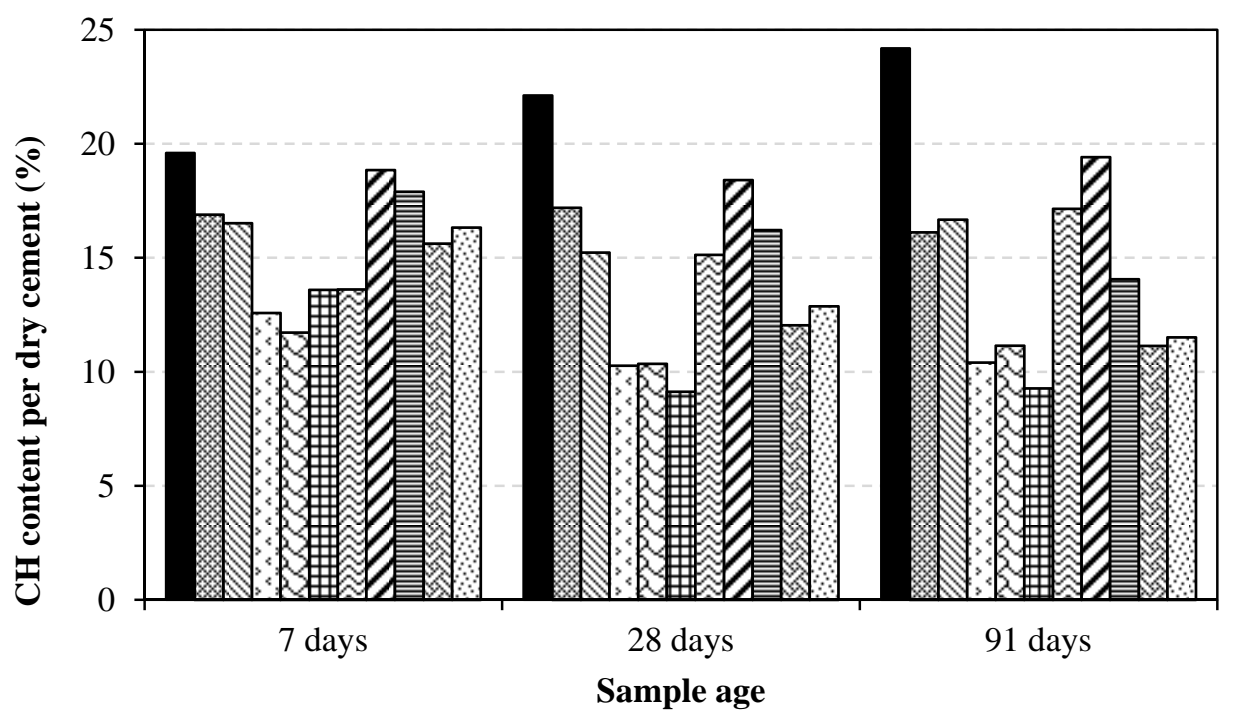

$\square \mathrm{OPC}$

족-Cont-500/2

$\triangle$ CSA-DW80-4-500/2

घCSA-HCl80-4-500/2

囚CSA-Sul.80-4-500/2

$\boxplus$ HLRA-500/2

曰CSA-Cont-650/1

口CSA-DW80-4-650/1

目CSA-HCl80-4-650/1

๑CSA-Sul.80-4-650/1

QHLRA-650/1

Fig. 13: CH content of cement paste samples

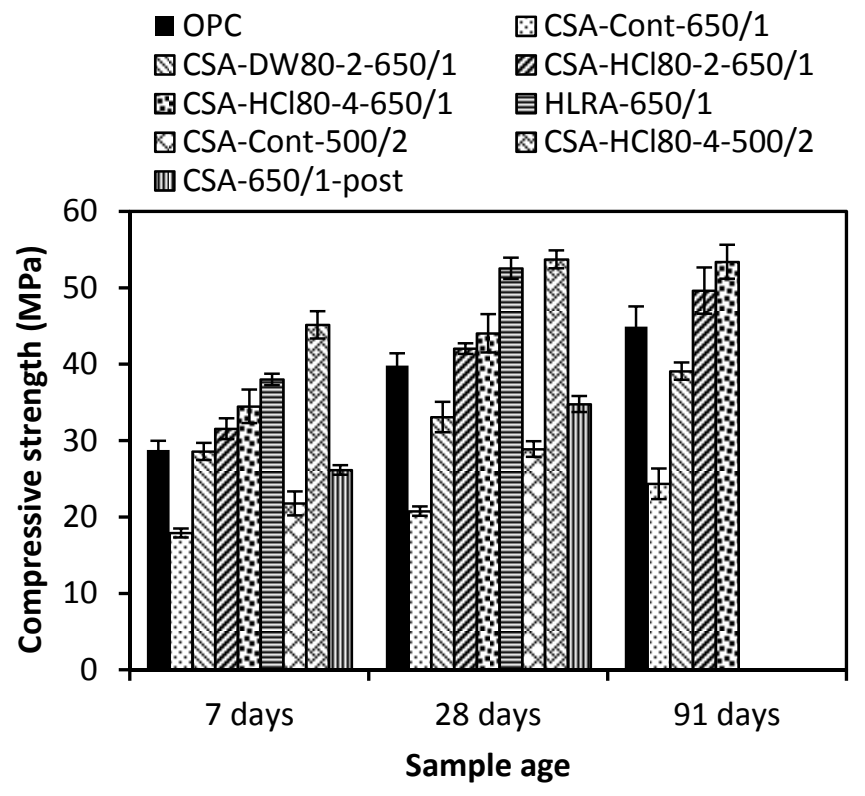

Fig. 14: Mortar cubes compressive strength 


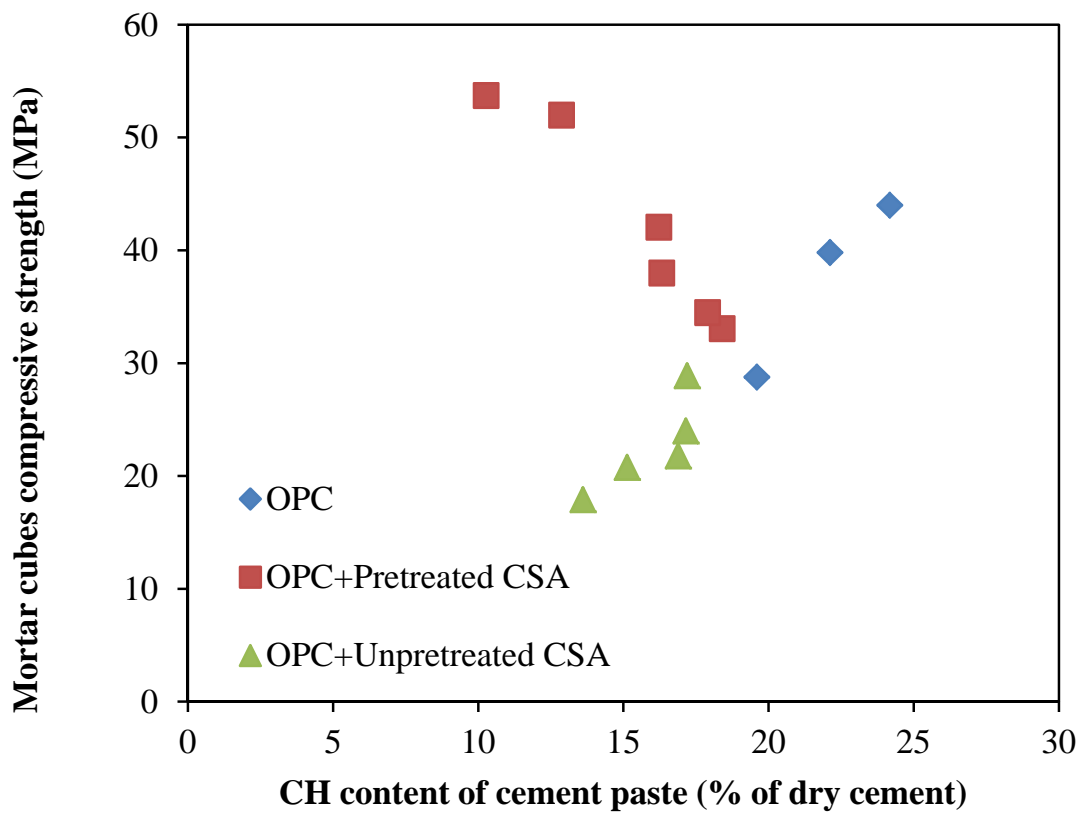

Figure 15: Mortar cubes compressive strength vs $\mathrm{CH}$ content of paste samples 
Table 1: Metal impurities concentrations measured in corn stover leachate

\begin{tabular}{|l|c|c|c|c|c|}
\hline \multirow{2}{*}{ Pretreatment } & \multicolumn{5}{|c|}{ Leachate Concentration (mg/g biomass) } \\
\cline { 2 - 6 } & $\mathrm{Na}$ & $\mathrm{K}$ & $\mathrm{Ca}$ & $\mathrm{Mg}$ & $\mathrm{P}$ \\
\hline $\mathrm{HCl} 23^{\circ} \mathrm{C}$ & 0.05 & 22.06 & 3.57 & 1.56 & 1.95 \\
$\mathrm{HCl} 80^{\circ} \mathrm{C}$ & 0.67 & 25.99 & 5.48 & 1.91 & 2.34 \\
$\mathrm{DW} 23^{\circ} \mathrm{C}$ & 0.04 & 19.12 & 1.19 & 0.99 & 1.34 \\
$\mathrm{DW} 80^{\circ} \mathrm{C}$ & 0.24 & 24.13 & 1.40 & 1.31 & 1.44 \\
$\mathrm{Sul} .80^{\circ} \mathrm{C}$ & 0.41 & 26.62 & 5.03 & 1.95 & 2.33 \\
\hline
\end{tabular}

Table 2: Chemical composition and physical properties of corn stover ash

\begin{tabular}{lcccccccccc}
\hline Sample ID & $\mathrm{SiO}_{2}$ & $\mathrm{Al2O} 3$ & $\mathrm{Fe} 2 \mathrm{O} 3$ & $\mathrm{CaO}$ & $\mathrm{MgO}$ & $\mathrm{P} 2 \mathrm{O} 5$ & $\mathrm{Na} 2 \mathrm{O}$ & $\mathrm{K} 2 \mathrm{O}$ & LOI & $\begin{array}{c}\mathrm{BET} \\
(\mathrm{m} 2 / \mathrm{gr})\end{array}$ \\
\hline CSA-HCL80-4-500/2 & 76.54 & 1.59 & 0.79 & 4.05 & 1 & 3.31 & 0.58 & 3.93 & 6.09 & 64 \\
CSA-HCL80-4-650/1 & 77.94 & 1.5 & 2.17 & 3.86 & 1.12 & 3.34 & 0.7 & 4.41 & 3.82 & 14.3 \\
CSA-DW80-4-650/1 & 47.37 & 1.67 & 2.65 & 14.5 & 3.29 & 6.06 & 0.57 & 10.56 & 10.64 & 10.6 \\
CSA-Cont-650/1 & 28.42 & 0.89 & 0.56 & 7.83 & 3.3 & 6.78 & 0.42 & 25.41 & 22.78 & 8.5 \\
HLRA-650/1 & 81.34 & 3.46 & 1.42 & 3.21 & 0.48 & 0.54 & 1.87 & 1.84 & 1.8 & 67 \\
Type I/II portland & 21.8 & 4.35 & 3.4 & 64.2 & 1.79 & -- & 0.17 & 0.52 & 0.89 & -- \\
Cement & & & & & & & & & & \\
\hline
\end{tabular}

Table 3: Loss on ignition (LOI) of biomass ash

\begin{tabular}{l|c|c|}
\hline \multirow{2}{*}{ Treatment type } & \multicolumn{2}{|c|}{ Burning condition } \\
\cline { 2 - 3 } & $500 / 2$ & $650 / 1$ \\
\hline CSA-Cont & 24.6 & 22.7 \\
CSA-DW80-2 & 13.6 & 12.3 \\
CSA-DW80-4 & 13.1 & 8.6 \\
CSA-HCl80-2 & 10 & 8.6 \\
CSA-HCl80-4 & 6 & 3.8 \\
CSA-Sul80-4 & 4.7 & 2.6 \\
HLRA & 2.3 & 1.8 \\
\hline
\end{tabular}

Data are given in percent of initial weight

Table 4: Post-treatment leachate concentrations

\begin{tabular}{c|c|c|c|c|c|}
\hline \multirow{2}{*}{ Sample ID } & \multicolumn{5}{|c|}{ Post-treatment leachate concentrations (mg/g of ash) } \\
\cline { 2 - 6 } & $\mathrm{P}$ & $\mathrm{Na}$ & $\mathrm{Ca}$ & $\mathrm{K}$ & $\mathrm{Mg}$ \\
\hline CSA-Cont-500/2 & 0.46 & 0.23 & 0.09 & 57.24 & 0.03 \\
CSA-Cont-650/1 & 4.50 & 0.33 & 0.09 & 58.73 & 0.04 \\
\hline
\end{tabular}

